\title{
Efeitos de um Programa de Prevenção à Violência no Namoro
}

\author{
Sheila Giardini Murta - Universidade de Brasília, Brasilia, Brasil \\ Rafael Alberto Moore - Universidade de Brasilia, Brasilia, Brasil \\ Ana Aparecida Vilela Miranda - Universidade de Brasília, Brasília, Brasil \\ Eudes Diógenes Alves Cangussú - Universidade de Brasilia, Brasilia, Brasil \\ Karine Brito dos Santos - Universidade de Brasília, Brasilia, Brasil \\ Karinne Leissa Torres Bezerra - Universidade de Brasilia, Brasília, Brasil \\ Lydia Galdino Veras - Universidade de Brasilia, Brasilia, Brasil
}

\begin{abstract}
Resumo
Este estudo avaliou os efeitos de uma intervenção para prevenção à violência no namoro sobre intenções de enfrentamento a esse tipo de violência, dificuldades em regulação das emoções e endosso a normas tradicionais de papéis de gênero masculino. Participaram 45 adolescentes, alocados não randomicamente em um grupo experimental $(N=21)$ e um grupo controle $(N=$ 24). A intervenção compreendeu nove sessões focadas em informações sobre violência no namoro, habilidades sociais, tomada de decisão, papéis de gênero, direitos sexuais e reprodutivos e empoderamento. Análises intra e entre grupos revelaram redução significativa em crenças que apoiam a restrição emocional como característica masculina no grupo experimental, ao passo que intenções de enfrentamento à violência no namoro e regulação emocional não sofreram mudanças significativas em nenhum dos grupos. Contudo, avaliações qualitativas evidenciaram a prática extrassessão de habilidades de autocontrole e expressão emocional, assertividade e empatia. Novos estudos, principalmente longitudinais, são recomendados para elucidar esses resultados. Palavras-chave: prevenção primária, programa de intervenção, habilidades sociais, namoro, violência interpessoal
\end{abstract}

\section{Effects of a Dating Violence Prevention Program}

\begin{abstract}
This study evaluated the effects of a dating violence prevention intervention on intentions of coping with this type of violence, difficulties in regulating emotions and endorsement of traditional male gender norms. There were 45 adolescent participants, not randomly placed in an experimental group $(N=21)$ and a control group $(N=24)$. The intervention encompassed nine sessions focused on information about dating violence, social skills, decision making, sexual and reproductive rights, and empowerment. Analyses intra and between groups had shown significant reduction in beliefs that supported emotional restriction as a masculinity characteristic in the experimental group, whereas the intentions of coping with dating violence and emotional regulation had not suffered significant changes in any of the Groups. However, qualitative evaluations had evidenced the external practice of self-control and emotional expression skills, assertiveness and empathy. New studies, mainly longitudinal, are recommended to elucidate these results.

Keywords: primary prevention, intervention program, social skills, dating, interpersonal violence
\end{abstract}

Efectos de un Programa de Prevención de la Violencia en el Noviazgo

\begin{abstract}
Resumen
Este estudio evaluó los efectos de una intervención para la prevención a la violencia en el noviazgo sobre cómo hacer frente a tales intenciones de violencia, dificultades en la regulación de las emociones y aprobación de normas tradicionales de roles de género masculino. Participaron 45 adolescentes, no asignados no aleatoriamente en un grupo experimental $(N=21)$ y un grupo de control $(N=24)$. La intervención consistió en nueve sesiones que se centraron en información sobre violencia en el noviazgo, habilidades sociales, toma de decisiones, roles de género, derechos sexuales y reproductivos y en la potenciación. Análisis intra y entre grupos revelaron una reducción significativa en las creencias que apoyan la restricción emocional como característica masculina en el grupo experimental, mientras que las intenciones de enfrentamiento a la violencia en el noviazgo y la regulación emocional no sufrieron cambios significativos en ninguno de los grupos. Pese a eso, las evaluaciones cualitativas mostraron la práctica externa al período de las sesiones de habilidades de autocontrol y expresión emocional, asertividad y empatía. Son recomendados nuevos estudios, principalmente longitudinales, para esclarecer estos resultados.

Palabras clave: prevención primaria, programa de intervención, habilidades sociales, noviazgo, violencia interpersonal
\end{abstract}

Esforços crescentes têm sido investidos na pesquisa em desenvolvimento e avaliação de programas para prevenção primária à violência no namoro, especialmente nos Estados Unidos e Canadá (Leen et al., 2013; Shorey et al., 2012). Esses programas são destinados a grupos de adolescentes e jovens recrutados, frequentemente, em ambiente escolar e universitário, independentemente de seu grau de exposição a riscos para a violência no namoro (prevenção universal), ou a grupos selecionados por apresentarem 
riscos para a violência no namoro, como terem sido vítimas de maus tratos na família ou terem testemunhado conflito interparental (prevenção seletiva), ou a jovens casais que experienciam sinais iniciais de violência no namoro, como ciúme excessivo (prevenção indicada). São majoritariamente destinados à população jovem e adolescente e, em menor escala, a adultos cuidadores, como professores (Ball, Kerig, \& Rosenbluth, 2009; Wolfe, Crooks, Chiodo, Hughes, \& Ellis, 2009) e técnicos esportivos (Miller et al., 2012). Variam quanto ao formato, incluindo intervenções de sessão única (Pick, Leenen, Givaudan, \& Prado, 2010), sessões intensivas e concentradas em dois dias consecutivos (Antle, Sullivan, Dryden, Karam, \& Barbee, 2011) e sessões múltiplas diluídas ao longo de semanas (Schwartz, Magee, Griffin, \& Dupuis, 2004). Em termos avaliativos, esses programas têm sido avaliados por meio de delineamentos com avaliações de pré e pós-teste, com ou sem grupos controle, usualmente com escalas e questionários, e mais raramente com entrevistas (Ball et al., 2009) e medidas observacionais (Wolfe et al., 2009), por vezes, incluindo avaliações de seguimento (Foshee et al., 2004).

As lições aprendidas com a implementação e avaliação de tais intervenções indicam direções para o aprimoramento de sua efetividade, especialmente quando realizadas em novos contextos (Murta, Santos, Martins, \& Oliveira, 2013). Esse é o caso do Brasil, onde são ainda poucos os estudos sobre violência no namoro (Antônio, Koller, \& Hokoda, 2012; Assis, Pesce, Minayo, Pires, \& Oliveira, 2011; Nascimento \& Cordeiro, 2011) e escassos os programas desenvolvidos para esse fim (Murta et al., 2013). Nesse sentido, críticas têm sido feitas aos programas cujo conteúdo se restringe à informação para reconhecimento da violência no namoro e mudança de atitudes de aceitação da violência (Clarey, Hokoda, \& Ulloa, 2010; Cornelius \& Resseguie, 2007; Muñoz-Rivas, Graña, \& González, 2011). Os programas estritamente focados em conhecimento e atitudes (Jaycox et al., 2006; Taylor, Stein, \& Burden, 2010), quando comparados a outros que ensinam competências interpessoais para manejo de conflitos na relação amorosa (Antle et al., 2011; Schwartz et al., 2004; Wolfe et al., 2009), parecem apresentar eficácia e efetividade menos robustas. Por isso, recomendações têm sido feitas para que os programas de prevenção à violência no namoro incluam habilidades para regulação das emoções e habilidades sociais para resolução de conflitos interpessoais.
A incorporação desses conteúdos aos programas preventivos à violência no namoro é coerente com estudos que apontam déficits em habilidades de negociação em conflitos (Cornelius, Shorey, \& Beebe, 2010) e em regulação das emoções (Wolf \& Foshee, 2003) como estando associados à perpetração da violência entre jovens parceiros. Evidências consistentes indicam que a exposição à violência intrafamiliar e a conflitos interparentais favorecem o desenvolvimento de apego inseguro, ensinam por modelação o uso de estratégias negativas de resolução de conflitos e impedem o aprendizado de habilidades de regulação das emoções (Creasey, 2002; Kinsfogel \& Grych, 2004; Kim, Pears, Capaldi, \& Owen, 2009; Riggs, Cusimano, \& Benson, 2011), contribuindo também para a banalização dos desequilíbrios de poder nos papéis de gênero. Dessa forma, adolescentes e jovens que tiveram experiências de violência em sua família de origem podem ter mais dificuldade em construir vínculos afetivos seguros na vida adulta. Além disso, podem apresentar prejuízos em habilidades para tomar consciência, compreender, aceitar e manejar emoções negativas, como ciúme e raiva, e inibir comportamentos impulsivos, fazendo uso de estratégias de comunicação destrutivas em episódios de conflito com o parceiro. Como mostra a Figura 1, tais déficits pessoais se originam em múltiplos contextos de interação, incluindo, além da família de origem, também os pares, a comunidade e a cultura (Assis et al., 2011).

A competência interpessoal e a regulação de emoções negativas, sobretudo a raiva, também têm sido discutidas à luz do desenvolvimento de papéis de gênero masculinos (McDermott, Schwartz, \& Trevathan-Minnis, 2012). A ideologia de masculinidade tradicional pressupõe como características do homem o controle emocional (não permissão para sentir e expressar emoções), a dureza emocional e física (suportar altos níveis de dor e renunciar ao cuidado) e a autossuficiência (obrigar-se a ser bem-sucedido e independente de ajuda) (Lease et al., 2010). A conformidade com tais normas tradicionais de papéis de gênero masculinos está associada à aceitação da violência nas relações íntimas (McDermott \& Lopez, 2013) e à supressão de emoções, prejudicando o desenvolvimento de habilidades sociais de autoexpressão emocional e empatia e favorecendo disfunções relacionais e em saúde para o homem (McDermott \& Lopez, 2013; Lease et al., 2010). Por conseguinte, o desenvolvimento de pensamento crítico acerca das estereotipias dos papéis de gênero masculinos e a promoção de habilidades para regular emoções, como ciúme e raiva, e lidar com conflitos interpessoais 


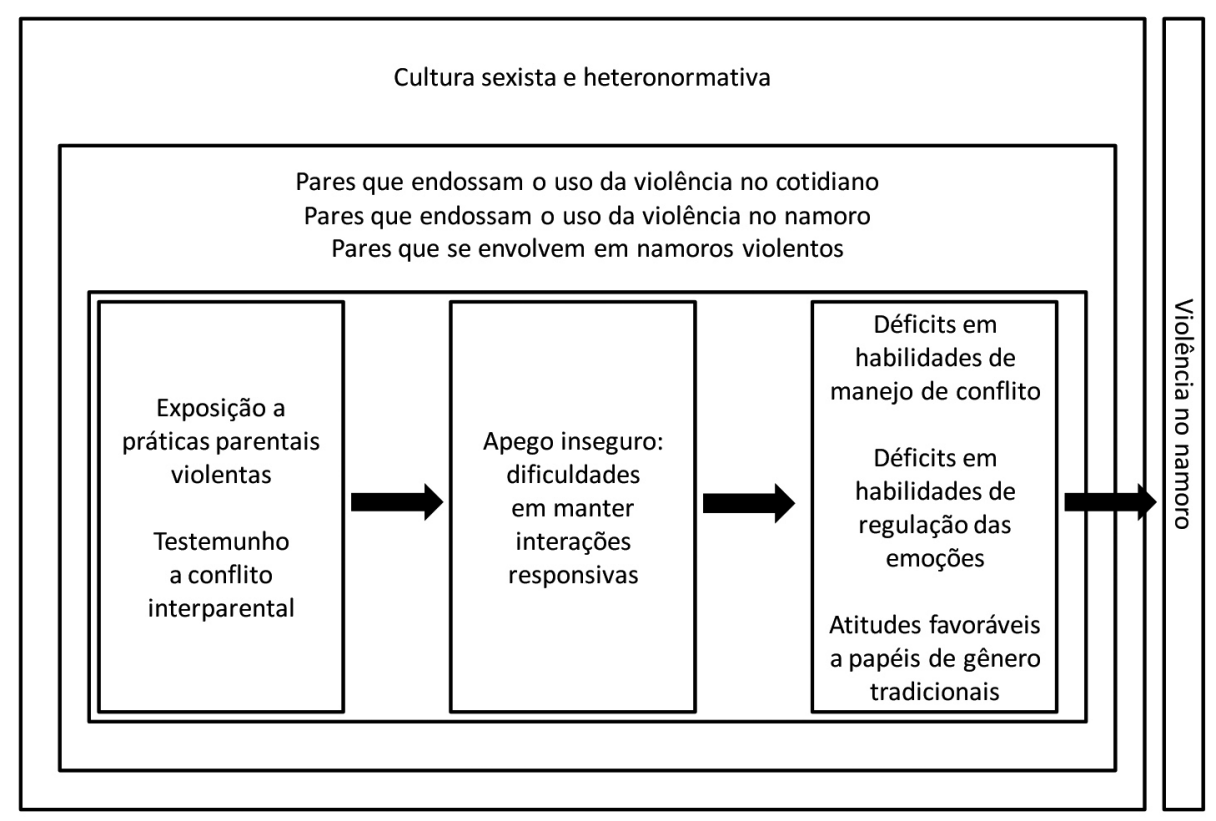

Figura 1. Fatores de risco para a violência no namoro.

seriam altamente indicadas em programas de prevenção primária à violência no namoro.

No Brasil, programas preventivos com esse foco são urgentes, conforme revelam dados epidemiológicos acerca da violência no namoro entre adolescentes brasileiros. Um estudo de âmbito nacional que avaliou 3.205 adolescentes em dez capitais brasileiras, encontrou que $86,9 \%$ dos jovens foram vítimas e 86,8\% já praticaram, em algum momento da vida, algum tipo agressão contra o parceiro, seja física, sexual, psicológica ou verbal (Oliveira, Assis, Njaime, \& Oliveira, 2011). As autoras verificaram ainda que $76,6 \%$ dos participantes são tanto vítimas como autores das diversas formas de violência. A bidirecionalidade da violência e as altas taxas de prevalência indicam que meninas e meninos brasileiros necessitam fortemente de ações preventivas.

Todavia, pesquisas em desenvolvimento e avaliação de programas de prevenção primária à violência no namoro são escassas no Brasil, ainda que seja abundante a produção em violência de gênero na conjugalidade e na adultez. Desenvolver e avaliar sistematicamente programas preventivos para adolescentes por meio do uso de avaliações abrangentes e rigorosas, com grupos de comparação e associação entre múltiplas medidas, é claramente uma das necessidades da área. O presente estudo visa suprir essa lacuna, por meio do desenvolvimento de um programa dirigido à prevenção à violência no namoro e avaliação com delineamento quase-experimental e triangulação de métodos.

Esse estudo teve por objetivo geral avaliar os efeitos da intervenção sobre intenções de enfrentamento à violência no namoro, dificuldades em regulação das emoções e endosso a normas tradicionais de papéis de gênero masculino entre os adolescentes participantes, em comparação a adolescentes que não receberam a intervenção. Em segundo lugar, buscou-se avaliar o processo da intervenção, por meio da descrição da prática de habilidades sociais ensinadas no decorrer do programa e da avaliação de satisfação para com a intervenção entre os adolescentes participantes da intervenção.

\section{Método}

\section{Participantes}

Participaram deste estudo 45 adolescentes, com idades variando entre 15 e 17 anos, estudantes do primeiro ano do ensino médio de uma escola pública de Brasília, DF. Do total de participantes, $72,4 \%$ eram mulheres e $27,6 \%$ eram homens; a maior parte deles $(75,8 \%)$ relatou já ter namorado anteriormente e uma menor parte $(24,13 \%)$ afirmou estar em um relacionamento amoroso no início do programa. 


\section{Delineamento}

$\mathrm{O}$ estudo foi realizado por meio de um delineamento quase-experimental, com grupos não equivalentes e avaliação de pré e pós-teste (Campbell \& Stanley, 1979) e triangulação de métodos. Os participantes do estudo foram selecionados não randomicamente. Projetos com temas transversais estavam sendo oferecidos no horário escolar e os alunos foram solicitados a se inscreverem naquele de seu interesse. Os alunos do turno matutino que escolheram o Programa de Habilidades de Vida foram alocados no grupo experimental (GE, $N=21 ; 54 \%$ meninas; idade média $=16,8$ anos). Os alunos do turno vespertino foram alocados no grupo controle (GC, $N=24 ; 57 \%$ meninas; idade média $=16,3$ anos).

\section{Instrumentos}

Questionário Sociodemográfico - Formado por 13 questões fechadas sobre idade, sexo, estado de origem, configuração familiar, profissão e instrução dos pais ou cuidadores, religião dos pais, problemas de saúde e histórico de relacionamento amoroso.

Sentenças Incompletas acerca de Intenção de Enfrentamento à Violência no Namoro - Instrumento qualitativo, elaborado por Murta et al. (2013; 2015), contendo seis sentenças incompletas que descrevem situações para potencial conflito na relação com o parceiro íntimo. As três primeiras descrevem cenários de vitimização: "Se meu/minha namorado/a tiver um jeito muito estourado/a, me criticar na frente dos outros, eu..."; "Se meu/minha namorado/a tiver muito ciúme de mim e me impedir de sair com meus/minhas amigos/as, eu..." e "Se meu/minha namorado/namorada ficar bravo/a comigo e espalhar mentiras sobre mim na internet, eu..." $\mathrm{E}$ as três últimas descrevem cenários de perpetração da violência: "Se meu/minha namorado/namorada me der motivos para eu ficar morrendo de ciúmes dele/dela, eu..."; "Se eu estiver com muita raiva do meu/minha namorado/a por um motivo justo, eu..." e "Se eu estiver magoada/o após uma briga com meu/minha namorado/a e achar uma ocasião para descontar, eu..." Em cada sentença, era solicitado ao participante que completasse as sentenças descrevendo o que faria na situação e como faria. Esse instrumento foi utilizado antes e após a intervenção.

Escala de Dificuldades de Regulação das Emoções - O instrumento foi construído por Gratz e Roemer (2004) para avaliar dificuldades na consciência, compreensão e aceitação das emoções. A escala original é composta por 36 itens e seis fatores: falta de consciência emocional, dificuldades de engajamento em comportamento dirigido a metas, dificuldades em controle de impulso, falta de clareza emocional, não aceitação de respostas emocionais e acesso limitado a estratégias de regulação emocional. Para o presente estudo, os itens foram traduzidos e adaptados para o português brasileiro. Adolescentes residentes no Distrito Federal, Bahia e Minas Gerais $(N=184)$ responderam ao instrumento. A análise paralela indicou a extração de três fatores. Fez-se uma análise fatorial exploratória por estimação de eixos principais e rotação oblimin. Foram identificados três fatores: falta de estratégias de regulação emocional, com nove itens (alfa de Cronbach $=0,88$; ex.: "Quando estou chateado, eu sinto que sou fraco"), consciência emocional, com cinco itens (alfa de Cronbach = 0,68; ex.: Quando estou chateado, eu tiro um tempo para pensar sobre como estou me sentindo) e dificuldade em controle de impulso, com cinco itens (alfa de Cronbach =0,82; ex.: Quando estou chateado, eu perco o controle sobre os meus comportamentos). A escala final consiste, portanto, em 19 itens, alocados nos três fatores referidos, que explicam 53,7 da variância. Esse instrumento foi utilizado na avaliação pré e pós-intervenção.

Escala de Significados da Masculinidade para Adolescentes - De autoria de Oransky e Fisher (2009), a escala avalia o endosso a normas tradicionais de papéis de gênero masculino. A escala original contém 27 itens agrupados nos fatores: esforço constante, restrição emocional, heterossexismo e chacota social. Para este estudo, o instrumento foi traduzido e adaptado para o português brasileiro. Em seguida, foi aplicado em 184 adolescentes das regiões centro-oeste, sudeste e nordeste do Brasil. A análise paralela indicou a extração de três fatores, corroborados por meio de análise fatorial exploratória por estimação de eixos principais e rotação promax: heterossexismo, com seis itens (alfa de Cronbach $=0,83$; ex.: É constrangedor ter muitos amigos gays); esforço constante, com quatro itens (alfa de Cronbach $=0,68$; ex.: Não importa o que aconteça, um homem deve parecer forte para os outros) e restrição emocional, com cinco itens (alfa de Cronbach = 0,75; ex.: Quando um homem tem algum medo, ele deve guardar isso para si). Os três fatores apresentam uma variância explicada de 54,7. Neste estudo, esse instrumento foi utilizado na avaliação de pré e pós-teste.

Instrumento de Avaliação de Dose Recebida - Trata-se de um formulário elaborado por Murta et al. (2013) em que o participante é solicitado a descrever por escrito, ao início de cada sessão, a partir 
da terceira sessão, as habilidades praticadas na última semana discutidas na sessão anterior ou em outras que a antecederam. Contém a instrução: "Nesta semana, o que você praticou do Programa de Habilidades de Vida? Praticar é todo pequeno passo: pensar, desejar ou agir... Escreva aqui". Contém também uma ilustração de pés caminhando, numa alusão a deslocamentos e mudanças graduais.

Escala de Satisfação com a Sessão - Nas duas primeiras sessões foi requisitado aos participantes que descrevessem sua (in)satisfação com a sessão com uma palavra ou expressão. Posteriormente essas palavras foram utilizadas para construir, conjuntamente com eles, a Escala de Satisfação com a Sessão, que foi aplicada ao final de cada sessão da terceira à nona sessão. Construiu-se uma escala de faces, com oito pontos, representando diferentes estados de satisfação e os rótulos correspondentes: horrível (1), péssimo (2), ruim (3), mais ou menos (4), "legalzinho" (5), "massa" (6), legal (7) e ótimo (8). O participante deveria marcar o item que melhor descrevia sua avaliação da sessão. $\mathrm{O}$ instrumento continha ainda um espaço para relatos que justificassem a escolha dessa resposta.

\section{Procedimentos}

Foi conduzida com os participantes do GE uma intervenção de nove encontros, uma vez por semana, com duração de 80 minutos cada, ao longo de nove semanas. O primeiro encontro foi destinado à apresentação e rapport, e o segundo e o último encontro foram utilizados para a aplicação dos instrumentos pré e pós-intervenção. Nas outras seis sessões, realizou-se a intervenção quando foram abordados sinais de violência no namoro; habilidades sociais assertivas, de manejo da raiva e de solução de problemas interpessoais; tomada de decisão; papéis de gênero; direitos sexuais e reprodutivos e empoderamento. Cada participante recebeu um guia, em formato de livro interativo, contendo os temas abordados na intervenção e exercícios de autoconhecimento (Murta et al., 2011), que eram utilizados como recurso complementar em cada sessão.

As sessões eram estruturadas em etapas que compreendiam: a) boas-vindas, avaliação da tarefa de casa e retomada da sessão anteriores com aplicação do Instrumento de Avaliação de Dose Recebida; b) apresentação do tema-chave da sessão, atividade vivencial ou dinâmica grupal visando o tema da sessão e uma abordagem crítica sobre ele, seguida do treino de habilidades sociais; c) psicoeducação por parte dos facilitadores tendo como objetivo corrigir crenças errôneas ou erros de pensamento, descobrir novas formas de enfrentamento e fortalecer as formas adaptativas apresentadas, e possibilitar empoderamento por meio de domínio de habilidades sociais; d) tarefa de casa visando treino e fixação dos temas da sessão e e) avaliação da sessão com a Escala de Satisfação. O procedimento completo utilizado em cada sessão está descrito em Murta et al. (2015).

As sessões foram conduzidas em grupo, durante o horário escolar, por três facilitadores. Estes foram previamente preparados para a condução das sessões por meio de supervisão semanal, leituras dirigidas, simulação e exposição direta aos procedimentos vivenciais, construção conjunta e seguimento de protocolos com a descrição dos objetivos e procedimentos da sessão e monitoramento de cada sessão. Tal monitoramento incluía o registro de comportamentos relevantes dos facilitadores e dos participantes ocorridos em cada sessão. No primeiro caso, os facilitadores deveriam observar e registrar suas habilidades sociais educativas emitidas na sessão (em forma de checklist), os sentimentos por eles experienciados e suas impressões sobre a sessão (em forma de registro contínuo). No segundo caso, era observado e registrado o engajamento dos jovens nas atividades, comportamentos indicadores de aproximação entre adolescentes e facilitadores (em forma de checklist) e os procedimentos implementados na sessão (em forma de registro contínuo) (Murta et al., 2012). Este estudo foi aprovado pelo Comitê de Ética em Pesquisa em Ciências Humanas da Universidade de Brasília.

Os participantes do GC não receberam nenhum tipo de intervenção, tendo unicamente respondido aos mesmos instrumentos de pré e pós-teste aplicados no GE.

\section{Análise dos Dados}

Foram feitas análises de comparação de médias intra e entre grupos com os dados provenientes das Escalas de Dificuldade em Regulação das Emoções e Significados da Masculinidade para Adolescentes. Para tanto, realizou-se o teste ANOVA mista. Os demais dados quantitativos foram analisados com estatística descritiva. Utilizou-se o software SPSS versão 18.

Os dados qualitativos provenientes da Avaliação de Dose Recebida, Escala de Satisfação e Sentenças Incompletas acerca de Intenção de Enfrentamento à Violência no Namoro foram analisados por meio de análise de conteúdo. Os dados dos dois primeiros instrumentos foram analisados exclusivamente por um 
pesquisador. No caso do último instrumento, o sistema de categorias foi construído, inicialmente, por um pesquisador e, em seguida, foi submetido a um juiz. A partir das discordâncias identificadas, foi reconstruído. Foram identificadas nove categorias, baseadas em Del Prette, Murta, Cangussú e Del Prette (2014), das quais cinco foram agrupadas em favorecedoras da qualidade da relação (adaptativas) e quatro foram consideradas desfavorecedoras da qualidade da relação (desadaptativas). As categorias de intenções adaptativas foram: assertividade, solução de problemas, autorregulação das emoções, empatia e perdão. As categorias desadaptativas foram: resignação, reação não responsiva, violência e vigilância.

\section{Resultados}

Conforme revelam os dados expostos nas Tabelas 1 e 2, os adolescentes de ambos os grupos, já ao início da intervenção, apresentavam majoritariamente intenções de enfrentamento à violência no namoro por meio de estratégias saudáveis, tanto na condição de vitimização quanto perpetração e, assim, permaneceram na avaliação pós-intervenção.

$\mathrm{Na}$ condição de vitimização (ver Tabela 1), ao se analisar as categorias de intenções favoráveis à qualidade da relação, as estratégias mais frequentemente relatadas, tanto antes quanto após a intervenção, em ambos os grupos, foram solução de problemas e assertividade. O número total de intenções favoráveis à qualidade da relação manteve-se praticamente estável antes e após a intervenção para ambas as condições experimentais. Contudo, ao se analisar por categorias específicas dentre as favoráveis à qualidade da relação, nota-se que a subcategoria assertividade teve um aumento de seis ocorrências no pós-teste para o grupo experimental, enquanto teve uma redução de cinco ocorrências para o grupo controle. Ainda na condição de vitimização, na categoria intenções desfavoráveis à qualidade da relação, constata-se que as categorias mais frequentemente relatadas, antes e após a intervenção, foram violência e reação não responsiva. Não são evidentes diferenças importantes entre os grupos e entre as avaliações pré e pós-teste em categorias que desfavorecem a qualidade da relação.

$\mathrm{Na}$ condição de perpetração (ver Tabela 2), nas categorias que favorecem a qualidade da relação, as mais frequentemente relatadas foram solução de problemas e regulação das emoções, para ambos os grupos, antes e após a intervenção. Os dados das categorias que favorecem a qualidade da relação para os grupos experimental e controle mantiveram-se sem mudanças importantes, ao se analisar eventuais diferenças entre o pré e pós-teste. Ainda na condição de perpetração, nas categorias que desfavorecem a qualidade da relação, as mais frequentes foram violência e resignação. Nota-se

Tabela 1

Frequência de Relatos de Intenção de Enfrentamento à Violência no Namoro em Situação de Vitimização em Categorias que Favorecem e Desfavorecem a Qualidade da Relação, entre Grupos Experimental (GE) e Controle (GC), Antes e Depois da Intervenção

\begin{tabular}{lcccc}
\hline & \multicolumn{2}{c}{ Pré-teste } & \multicolumn{2}{c}{ Pós-teste } \\
\cline { 2 - 5 } & GE & GC & GE & GC \\
\hline Categorias que favorecem a qualidade da relação & & & & 13 \\
$\quad$ Assertividade & 20 & 18 & 26 & 67 \\
Solução de problemas & 71 & 68 & 60 & 7 \\
Regulação das emoções & 12 & 8 & 9 & 0 \\
Empatia & 1 & 0 & 1 & 87 \\
Total & 104 & 94 & 96 & 7 \\
Categorias que desfavorecem a qualidade da relação & & & & 5 \\
Resignação & 2 & 6 & 4 & 11 \\
Reação não responsiva & 8 & 9 & 4 & 23 \\
Violência & 2 & 10 & 6 & 14 \\
Total & 12 & 25 & & 23 \\
\hline
\end{tabular}


uma discreta redução em intenções de violência para o grupo experimental (três ocorrências), e um pequeno aumento nessa mesma modalidade de intenção para o grupo controle (três ocorrências). Em resumo, a análise das sentenças incompletas indica duas tendências positivas, favoráveis ao grupo experimental, com aumento em intenção de respostas assertivas na condição de vitimização e redução em respostas violentas na condição de perpetração, ao passo que nas demais categorias não foram identificadas mudanças.

A análise dos dados intra e entre grupos obtidos por meio da Escala de Dificuldades em Regulação das Emoções, conduzida por meio de ANOVA mista, revelou ausência de efeitos significativos entre os grupos experimental e controle, antes e após a intervenção, para os três fatores: falta de estratégia de regulação emocional [F lambda de Wilks $(1,43)=0,79 ; p=0,38$; $\left.\mathrm{Eta}^{2}=0,02\right]$, consciência emocional [F lambda de Wilks $\left.(1,43)=0,02 ; p=0,89 ; \mathrm{Eta}^{2}=0,00\right]$ e falta de controle de impulso [F lambda de Wilks $(1,43)=0,32 ; p=0,57$; $\left.\mathrm{Eta}^{2}=0,01\right]$. As médias e desvios-padrão pré e pós-intervenção dos grupos experimental e controle estão disponíveis na Tabela 3.

Uma comparação entre as médias obtidas antes e após a intervenção (Tabela 3), para os dois grupos experimentais, nos dados da Escala de Significados da Masculinidade para Adolescentes, por meio de ANOVA mista, revelou ausência de efeitos significativos para os fatores heterossexismo [F lambda de Wilks $(1,43)$ $\left.=0,67 ; p=0,41 ; \mathrm{Eta}^{2}=0,01\right]$, e esforço constante $[\mathrm{F}$ lambda de Wilks $\left.(1,43)=0,11 ; p=0,74 ; \mathrm{Eta}^{2}=0,00\right]$, mas efeito significativo no fator restrição emocional [F lambda de Wilks $(1,43)=4,56 ; p=0,04 ; \mathrm{Eta}^{2}=$ $0,09]$. Em outras palavras, os participantes do grupo experimental, comparados ao grupo controle, tiveram redução significativa em atitudes de endosso a normas tradicionais de papéis de gênero, no que diz respeito à restrição emocional.

\section{Avaliação de Processo}

Foram registrados 129 relatos no Instrumento de Avaliação de Dose Recebida, ao longo de seis sessões, acerca de práticas de habilidades ensinadas na intervenção. Essas respostas foram, primeiramente, classificadas em 1) agir específico, quando descreve ter feito alguma ação, como pensar, conversar, observar, refletir e especifica essa ação; 2) agir inespecífico, quando descreve ter feito algo sem descrever o que foi feito; e 3) não ação, quando o participante descreve não ter realizado nada ou não se lembrar.

Foram encontrados $77(59,7 \%)$ relatos na categoria agir específico, $31(24,01 \%)$ na categoria agir inespecífico e 21 (16,29\%) na categoria não ação. Dos relatos na categoria agir específico, foram extraídos aqueles que continham elementos relacionados às habilidades de negociação de conflitos e regulação das emoções.

Tabela 2

Frequência de Relatos de Intenção de Enfrentamento à Violência no Namoro em Situação de Perpetração em Categorias que Favorecem e Desfavorecem a Qualidade da Relação, entre Grupo Experimental (Ge) e Grupo Controle (Gc), Antes e Depois da Intervenção

\begin{tabular}{lcccc}
\hline & \multicolumn{2}{c}{ Pré-teste } & \multicolumn{2}{c}{ Pós-teste } \\
\cline { 2 - 5 } & GE & GC & GE & GC \\
\hline Categorias que favorecem a qualidade da relação & & & & 9 \\
Assertividade & 16 & 10 & 47 & 44 \\
Solução de problemas & 39 & 46 & 42 & 25 \\
Regulação das emoções & 25 & 23 & 20 & 0 \\
Perdão & 1 & 0 & 1 & 78 \\
Total & 81 & 79 & 80 & 3 \\
Categorias que desfavorecem a qualidade da relação & & & & 3 \\
Resignação & 2 & 8 & 2 & 11 \\
Reação não responsiva & 0 & 0 & 0 & 1 \\
Violência & 13 & 8 & 10 & 18 \\
Vigia Parceiro & 0 & 1 & 0 & 12 \\
Total & 15 & 17 & & 3 \\
\hline
\end{tabular}


Estas foram categorizadas em três classes: autocontrole e expressão das emoções (33 relatos), assertividade (7 relatos) e empatia (7 relatos).

As respostas mais frequentemente encontradas foram relativas à categoria autocontrole e expressão de emoções. Nestes, os adolescentes fizeram referência a situações onde conseguiram reconhecer em si diversas emoções e os efeitos destas, em que as mais comuns foram raiva e ciúme. Também relataram terem encontrado maneiras de lidar com esses sentimentos, como acalmar-se, controlar o ciúme, pensar antes de agir, não agir precipitadamente em momentos de raiva e aliviar a raiva em atividades saudáveis, como praticar esportes e conversar com alguém. Relatos ilustrativos dessa categoria são: "Refleti um pouco das minhas atitudes, e descontei a minha raiva jogando futebol..." e "Observei esses dias que quando estou sentindo raiva de algo, se eu não falar para alguém o que eu estou sentindo eu fico me sentindo mal".
Os relatos nas categorias empatia e assertividade foram menos frequentes do que autocontrole e expressão das emoções. Na categoria empatia, os participantes referiram situações em que puderam notar o impacto de suas ações sobre os outros e que mudaram sua forma de agir para não magoar outras pessoas (por exemplo: "Pensar bem antes de fazer algo que machuque alguém"). Na categoria assertividade, foram incluídos relatos em que mencionavam práticas relativas à expressão de sentimentos e necessidades pessoais para outras pessoas (por exemplo: "Aprendi que é muito importante se impor em um relacionamento, que você tem que conversar").

A avaliação de satisfação com a sessão evidenciou alta satisfação com o programa, com médias de satisfação variando entre 6,69 (sessão 7) a 7,83 (sessão 9). A Tabela 4 demonstra que as médias obtidas em cada sessão na Escala de Satisfação com a Sessão foram altas (todas acima de 6 em uma escala de 1-8), assim como

Tabela 3

Médias e Desvios-Padrão de Fatores em Normas de Papéis de Gênero e Dificuldades em Regulação das Emoções nos Grupos Experimental $(N=21)$ e Controle $(N=24)$, Antes e Após a Intervenção

\begin{tabular}{|c|c|c|c|c|}
\hline \multirow[t]{2}{*}{ Variáveis de interesse } & \multicolumn{2}{|c|}{ Pré-intervenção } & \multicolumn{2}{|c|}{ Pós-Intervenção } \\
\hline & GE & GC & GE & GC \\
\hline & Média (DP) & Média (DP) & Média (DP) & Média (DP) \\
\hline \multicolumn{5}{|l|}{ Dificuldades em regulação das emoções } \\
\hline Falta de controle de impulso & $1,97(0,79)$ & $2,03(0,81)$ & $1,80(0,60)$ & $2,05(0,74)$ \\
\hline Falta de consciência emocional & $3,20(0,92)$ & $3,28(1,09)$ & $3,46(0,86)$ & $3,21(0,97)$ \\
\hline Falta de estratégias de regulação amocional & $1,97(0,95)$ & $2,18(0,93)$ & $2,17(0,97)$ & $1,92(0,71)$ \\
\hline \multicolumn{5}{|l|}{ Endosso a normas tradicionais de papéis de gênero } \\
\hline Restrição emocional & $1,73(0,50)$ & $1,81(0,56)$ & $1,51(0,40)^{*}$ & $1,99(0,68)$ \\
\hline Heterossexismo & $2,06(0,58)$ & $2,42(0,55)$ & $1,99(0,57)$ & $2,18(0,66)$ \\
\hline Esforço constante & $2,25(0,55)$ & $2,60(0,61)$ & $2,06(0,56)$ & $2,29(0,64)$ \\
\hline * Mudança significativa $p<0,5$ & & & & \\
\hline
\end{tabular}

Tabela 4

Médias da Escala de Satisfação com a Sessão

\begin{tabular}{lccccccc}
\hline Sessão & 4 & 5 & 6 & 7 & 8 & 9 & Total \\
\hline Média & 6,72 & 6,89 & 6,76 & 6,69 & 7 & 7,83 & 6,98 \\
Máximo & 8 & 8 & 8 & 8 & 8 & 8 & - \\
Mínimo & 5 & 6 & 4 & 4 & 5 & 7 & - \\
\hline
\end{tabular}

Nota. 1 = sessão "horrível”; 8 = sessão "ótima". 
a média geral. Foram relatadas 130 respostas que justificavam a resposta escolhida na Escala de Satisfação. Estas foram agrupadas em seis categorias: interessante e divertido (31,5\%), novas aprendizagens (17,7\%), espaço para a expressão $(16,1 \%)$, relação com os outros $(13,1 \%)$, aplicabilidade na vida (10\%) e outros $(11,5 \%)$.

\section{Discussão}

Os resultados sugerem que a intervenção foi parcialmente eficaz, com redução significativa para o grupo experimental em atitudes que endossam papéis de gênero masculinos caracterizados por restrição emocional, aumento em intenções de uso de estratégias não violentas de enfrentamento a conflitos no namoro e indicadores qualitativos de desenvolvimento de habilidades interpessoais no decorrer da intervenção. Essas evidências encontram-se alinhadas ao conteúdo multicomponente abordado na intervenção, dirigido não apenas ao reconhecimento da violência no namoro, mas também ao desenvolvimento de habilidades sociais, pensamento crítico acerca de papéis de gênero, direitos sexuais e reprodutivos e protagonismo do adolescente (Murta et al., 2011, 2015). Tais dados são positivos e indicam uma redução em crenças estereotipadas sobre papéis de gênero masculinos, um dos fatores de risco para a violência no namoro (Lease et al., 2010; Minayo, Assis, \& Njaine, 2011; McDermott \& Lopez, 2013). Os achados das avaliações qualitativas foram igualmente favoráveis ao grupo experimental, com aumento em intenção de respostas assertivas na condição de vitimização e redução em respostas violentas na condição de perpetração. Esses resultados são coerentes com a avaliação de dose recebida, conduzida ao longo da intervenção, que apontou prática de habilidades sociais de autocontrole e expressão das emoções, assertividade e empatia.

Se por um lado os achados foram positivos em relação ao pensamento crítico acerca do papel de gênero masculino, no que diz respeito ao enfraquecimento da crença de que a restrição emocional é característica da masculinidade, por outro constatou-se ausência de efeitos significativos na medida de dificuldade de regulação das emoções. Esse dado contrasta com a avaliação qualitativa, que apontou uma prática bastante frequente de habilidades de autocontrole e expressão das emoções. Esses resultados quantitativos se contrapõem, em parte, aos obtidos em estudos que avaliam intervenções para prevenção à violência no namoro e fazem uso do ensino de habilidades sociais para manejo de conflitos nas relações amorosas em adolescentes (Antle et al., 2011; Schwartz et al., 2004; Wolfe et al., 2009) e identificaram resultados mais favoráveis em regulação das emoções após a intervenção. É possível que o instrumento usado neste estudo seja pouco sensível e inapropriado para o público juvenil. Novos instrumentos, mais focados em regulação das emoções em interações românticas entre adolescentes, devem ser desenvolvidos para uso em estudos futuros. Pode-se também especular que mudanças em regulação das emoções requerem mais tempo para se manifestar. Replicações deste estudo com avaliações de seguimento podem esclarecer tal questão.

Outra hipótese para explicar a diferença de efeitos em regulação das emoções seria uma fragilidade da intervenção quanto ao seu conteúdo, procedimentos e qualidade da relação facilitadores-adolescentes. Entretanto, o programa baseou-se em revisão de literatura prévia e sua implementação foi monitorada, por meio de medidas de auto-observação, a fim de se promover a integridade ou fidelidade da intervenção. Esses cuidados tendem a enfraquecer a referida hipótese, acerca da fragilidade da intervenção ou de sua implementação. A avaliação de satisfação com a sessão, marcadamente positiva, também corrobora essa interpretação. Entretanto, estudos futuros devem incluir medidas observacionais do desempenho dos facilitadores, a fim de se viabilizar análises mais precisas acerca do possível papel mediador ou moderador de tal desempenho sobre os resultados finais.

Os dados relativos à intenção de enfrentamento à violência no namoro chamam a atenção por apontarem, predominantemente, intenções saudáveis de enfrentamento à violência no namoro, em ambos os grupos. Em que pese a desejabilidade social do instrumento, essa parecia ser uma amostra relativamente saudável, tipicamente utilizada em prevenção universal (não selecionada por ser exposta a fatores de risco ou por apresentar sinais precoces de violência interpessoal), desde o início da intervenção. Há que se salientar que os participantes eram oriundos de uma escola pública da Asa Norte, em Brasília, região de alto poder aquisitivo e grau de instrução. Contudo, a ausência de medidas de fatores de risco para a violência no namoro, como exposição a maus tratos e conflito interparental na família de origem e estilo de apego, impede conclusões acerca das vulnerabilidades e recursos vividos pelos participantes. Novos estudos devem incluir avaliações dessas variáveis e identificar se atuam como mediadoras e moderadoras dos resultados. 
Deve-se notar como limitação neste estudo a amostra pequena e selecionada independente da exposição ao risco para a violência no namoro (prevenção universal), que pode ter contribuído para o baixo poder estatístico e, consequentemente, para a não identificação de efeitos significativos entre grupos e intragrupos na variável regulação emocional. Nesse caso, as características e tamanho da amostra podem ter dificultado a detecção de diferenças significativas em regulação das emoções entre ambas as condições experimentais, conforme já discutido em outros estudos de avaliação de programas de prevenção universal (Muñoz, Cuijpers, Smit, Barrera, \& Leykin, 2010). É possível que uma amostra mais exposta a riscos (como é o caso de programas de prevenção seletiva), como adolescentes provenientes de famílias que vivenciam violência intrafamiliar, apresente efeitos mais salientes estatisticamente.

Em conclusão, os resultados aqui encontrados, derivados de uma intervenção inovadora no cenário nacional, com delineamento quase-experimental e triangulação de métodos, mostram-se, a um só tempo, promissores e encorajadores de uma agenda de pesquisa. Constatou-se redução de atitudes de endosso a papéis de gênero masculinos com restrição emocional, aumento em intenção de respostas assertivas na condição de vitimização, redução em intenção de respostas violentas na condição de perpetração e prática de habilidades sociais de autocontrole e expressão das emoções, assertividade e empatia. Esses resultados, se mantidos ao longo do tempo, podem favorecer soluções não violentas para os conflitos nas relações íntimas e enfraquecer crenças relativas a papéis de gênero tradicionais. Dada a alta prevalência de violência no namoro em adolescentes brasileiros (Oliveira et al., 2011) e a escassez de programas nacionais baseados em evidências para prevenção primária à violência no namoro (Murta et al., 2013), considera-se que o presente estudo representa uma iniciativa relevante, com potencial contribuição para o campo da saúde mental do adolescente e para as políticas públicas de redução de sexismo e enfrentamento à violência contra a mulher (Secretaria de Políticas Públicas para as Mulheres, 2008).

As contradições encontradas nos resultados, referentes à mudança em habilidades de regulação das emoções, devem ser alvo de investigação em novos estudos. É recomendada a replicação deste estudo, com aprimoramentos sucessivos em suas medidas e delineamento. Avaliações de seguimento devem ser conduzidas para se identificar a manutenção, ampliação ou perdas dos resultados, assim como o impacto ao longo do tempo em indicadores de vitimização e perpetração.
Caso os resultados em habilidades sociais e crítica à restrição emocional como característica masculina venham a se manter e as intenções de enfrentamento não violento a conflitos se concretizem, é esperada uma redução no risco para a perpetração e vitimização para a violência no namoro (Lease et al., 2010; McDermott \& Lopez, 2013). Trata-se de um efeito auspicioso, podendo impactar a saúde mental dos adolescentes participantes, de seus parceiros e descendentes.

\section{Referências}

Antônio, T., Koller, S. H., \& Hokoda, A. (2012). Peer influences on the dating aggression process among Brazilian street youth: A brief report. Journal of Interpersonal Violence, 27(8), 1579-1592. doi: 10.1177/0886260511425794

Antle, B. F., Sullivan, D. J., Dryden, A., Karam, E. A., \& Barbee, A. P. (2011). Healthy relationship education for dating violence prevention among high-risk youth. Children and Youth Services Review, 33(1), 173179. doi:10.1016/j.childyouth.2010.08.031

Assis, S. G., Pesce, R. P., Minayo, M. C. S., Pires, T. O., \& Oliveira, R. V. C. (2011) Violência na família, na escola e na comunidade e relações afetivo-sexuais. Em M. M. Minayo, S. G. Assis, \& K. Njaine (Eds.), Amor e violência: um paradoxo das relações de amor e do ficar (pp. 153-182). Rio de Janeiro: Fiocruz.

Ball, B., Kerig, P., \& Rosenbluth, B. (2009). "Like a family but better because you can actually trust each other": The expect respect dating violence prevention program for at-risk youth. Health Promotion Practice, 10(1), 45S-58S. doi: 10.1177/1524839908322115

Campbell, D. T. \& Stanley, J. C. (1979). Delineamentos experimentais e quase-experimentais de pesquisa (R. A.T. Di Dio, Trad.). São Paulo: EPU e EDUSP (Trabalho original publicado em 1963).

Clarey, A., Hokoda, A. \& Ulloa, E. C. (2010). Anger control and acceptance of violence as mediators in the relationship between exposure to interparental conflict and dating violence perpetration in Mexican adolescents. Journal of Family Violence, 25(5), 619-625. http://link.springer.com/article/10.100 7\%2Fs10896-010-9315-7

Cornelius, T. L. \& Resseguie, N. (2007). Primary and secondary prevention programs for dating violence: A review of the literature. Aggression and Violent Behavior, 12(1), 364-375. doi:10.1016/j. avb.2006.09.006 
Cornelius, T. L., Shorey, R. C., \& Beebe, S. M. (2010). Self-reported communication variables and dating violence: Using Gottman's marital communication conceptualization. Journal of Family Violence, 25(4), 439-448. http://link.springer.com/article/10.1007 \%2Fs10896-010-9305-9

Creasey, G. (2002). Association between working models of attachment and conflict management behavior in romantic couples. Journal of Counseling Psychology, 49(3), 365-375. doi: 10.1037//0022-0167.49.3.365

Del Prette, Z. A. P., Murta, S. G., Cangussú, E. D. A., \& Del Prette, A. (2014). Habilidades sociais, estresse e violência no namoro. Em M. Lipp \& V. Tricoli (Eds.), Relacionamentos Interpessoais no Século XXI e o Stress Emocional (pp. 150-183). Novo Hamburgo: Sinopsys.

Foshee, V. A., Bauman, K. E., Ennet, S., Linder, G. F., Benefield, T. \& Suchindran, C. (2004). Assessing the long-term effects of the Safe Dates Program and a booster in preventing and reducing adolescent dating violence victimization and perpetration. American Journal of Public Health, 94(4), 619-624. Recuperado de http://www.ncbi.nlm. nih.gov/pmc/articles/PMC1448308/

Gratz, K. L. \& Roemer, L. (2004). Multidimensional assessment of emotion regulation and dysregulation: Development, factor structure, and initial validation of the Difficulties in Emotion Regulation Scale. Journal of Psychopathology and Behavioral Assessment, 26(1), 41-54. http://link.springer.com/articl e/10.1023\%2FB\%3AJOBA.0000007455.08539.94

Jaycox, L. H., Mccaffrey, D., Eiseman, B., Aronoff, J., Shelley, G. A., Collins, R. L., \& Marshall, G. N. (2006). Impact of a school-based dating violence prevention program among latino teens: Randomized controlled effectiveness trial. Journal of Adolescent Health, 39(5), 694-704. Recuperado de http://www.ncbi.nlm.nih.gov/pubmed/17046506

Kim, H. K., Pears, K. C., Capaldi, D. M., \& Owen, L. D. (2009). Emotion dysregulation in the intergenerational transmission of romantic relationship conflict. Journal of Family Psychology, 23(4), 585-595. doi: 10.1037/a0015935

Kinsfogel, K. M. \& Grych, J. H. (2004). Interparental conflict and adolescent dating relationships: Integrating cognitive, emotional, and peer influences. Journal of Family Psychology, 18(3), 505-515.
Recuperado de http://www.ncbi.nlm.nih.gov/ pubmed/15382975

Lease, S. H., Hampton, A. V., Fleming, K. M., Baggett, L. R., Montes, S. H., \& Sawyer, R. J. (2010). Masculinity and interpersonal competencies: Contrasting white and African American men. Psychology of Men \& Masculinity, 11(3), 195-207. doi: 10.1037/ a0018092

Leen, E., Sorbring, E., Mawer, M., Holdsworth, E., Helsing, B., \& Bowen, E. (2013). Prevalence, dynamic risk factors and the efficacy of primary interventions for adolescent dating violence: An international review. Aggression and Violent Behavior, 18(1), 159-174. doi:10.1016/j.avb.2012.11.015

McDermott, R. C. \& Lopez, F. G. (2013). College men's intimate partner violence attitudes: Contributions of adult attachment and gender role stress. Journal of Counseling Psychology, 60(1), 127-136. doi: 10.1037/a0030353.

McDermott, R. C., Schwartz, J. P., \& Trevathan-Minnis, M. (2012). Predicting men's anger management: Relationships with gender role journey and entitlement. Psychology of Men \& Masculinity, 13(1), 49-64. doi: $10.1037 /$ a0022689

Miller, E., Tancredi, D. J., McCauley, L. H., Decker, M. R., Virata, M. C. D., Anderson, H. A., Stetkevich, N., Brown, E. W., Moideen, F., \& Silveman, J. G. (2012). "Coaching boys into men:" a cluster-randomized controlled trial of a dating violence prevention program. Journal of Adolescent Health, 51(5), 431438. doi: 10.1016/j.jadohealth.2012.01.018.

Minayo, M. C. S., Assis, S. G., \& Njaine, K. (2011). É possível construir relações amorosas sem violência? Em M. M. Minayo, S. G. Assis, \& K. Njaine (Eds.), Amor e violência: um paradoxo das relaçôes de amor e do ficar (pp. 207-212). Rio de Janeiro: Fiocruz.

Muñoz, R. F., Cuijpers, F., Smit, F., Barrera, A. Z., \& Leykin, Y. (2010). Prevention of major depression. Annual Review of Clinical Psychology, 6(1), 181-212. doi: 10.1146/annurev-clinpsy-033109-132040.

Muñoz-Rivas, M. J., Graña, J. L., \& González, M. P. (2011). Abuso psicológico en parejas jóvenes. Psicología Conductual, 19(1), 117-131.

Murta, S. G., Miranda, A. A. V., Bezerra, K. L. T., Galdino, L., Santos, K. B. Cangussú, E. D. A., \& Moore, R. A. (2015). Programa de prevenção à 
violência no namoro e promoção de empoderamento em adolescentes. Em S. G. Murta, J. S. N. F. Bucher-Maluschke \& G. R. Diniz (Eds.). Violência no Namoro: Estudos, Prevenção e Psicoterapia (pp. 205228). Curitiba: Editora Appris.

Murta, S. G., Rosa, I. O., Menezes, J. C. L., Rieiro, M. R. S., Borges, O. S., Paulo, S. G., Oliveira, V., Ribeiro, D. C., Del Prette, A., \& Del Prette, Z. (2012). Direitos sexuais e reprodutivos na escola: avaliação qualitativa de um estudo piloto. Psicologia: Teoria e Pesquisa, 28, 335-344.

Murta, S. G., Santos, B. R. P., Martins, C.P. S., \& Oliveira, B. (2013). Prevenção primária à violência no namoro: Uma revisão de literatura. Contextos Clínicos, 6(2), 117-131. doi: 10.4013/ctc.2013.62.05

Murta, S. G., Santos, B. R. P., Nobre, L. A., Araújo, I. F., Miranda, A. A. V., Rodrigues, Í. O., \& Franco, C. T. P. (2013). Prevenção à violência no namoro e promoção de habilidades de vida em adolescentes. Revista de Psicologia da USP, 24(2), 263-288. doi: 10.1590/S0103-65642013000200005.

Murta, S. G., Santos, B. R. P., Nobre, L. A., Oliveira, S. A., Diniz, G. R. S., Rodrigues, Í. O., Miranda, A. A. V., Araújo, I, F., Del Prette, A., \& Del Prette, Z. A. (2011). Diferenciando baladas de ciladas: um guia para o empoderamento de adolescentes em relacionamentos intimos. Brasilia: Letras Livres.

Nascimento, F. S. \& Cordeiro, R. L. M. (2011). Violência no namoro para jovens moradores de Recife. Psicologia \& Sociedade, 23(3), 516-525. http:// dx.doi. org/10.1590/S0102-71822011000300009

Oliveira, Q. B. M., Assis, S. G., Njaine, K., \& Oliveira, R. V. C. (2011) Violência nas relações afetivo-sexuais. Em M. M. Minayo, S. G. Assis \& K. Njaine (Eds.). Amor e violência: um paradoxo das relações de amor e do ficar (pp. 87-140). Rio de Janeiro: Fiocruz.

Oransky, M. \& Fisher, C. (2009). The development and validation of the Meanings of Adolescent Masculinity Scale. Psychology of Men \& Masculinity, 10(1), 57-72. Recuperado de http://psycnet.apa.org/index. cfm?fa=buy.option'ToBuy\&id=2009-00130-005

Pick, S., Leenen, I., Givaudan, M., \& Prado, A. (2010).”Yo quiero, yo puedo... prevenir la violencia": Programa breve de sensibilización sobre violencia en el noviazgo. Salud Mental, 33(2), 153160. Recuperado de http://www.redalyc.org/ articulo.oa?id $=58215623006$
Riggs, S. A., Cusimano, A. M., \& Benson, K. M. (2011). Childhood emotional abuse and attachment processes in the dyadic adjustment of dating couples. Journal of Counseling Psychology, 58(1), 126-138. doi: $10.1037 / \mathrm{a} 0021319$

Schwartz, J. P., Magee, M. M., Griffin, L. D., \& Dupuis, C. W. (2004). Effects of a group preventive intervention on risk and protective factors related to dating violence. Group Dynamics: Theory, Research and Practice, 8(3), 221-231. doi: 10.1037/1089-2699.8.3.221

Secretaria Especial de Políticas para as Mulheres (2008). II Plano Nacional de Políticas para as Mulheres. Brasília: Presidência da República/Secretaria Especial de Políticas para as Mulheres.

Shorey, R. C., Zucosky, H., Brasfield, H., Febres, J., Cornelius, T. L., Sage, C., \& Stuart, G. L. (2012). Dating violence prevention programming: Directions for future interventions. Agression and Violent Behavior, 17(4), 289-296. doi:10.1016/j.avb.2012.03.001

Taylor, B. G., Stein, N., \& Burden, F. F. (2010). Exploring gender differences in dating violence/ harassment prevention programming in middle schools: Results from a randomized experiment. Journal of Experimental Criminology, 6(4), 419-445. Recuperado de http://link.springer.com/article/1 0.1007\%2Fs11292-010-9103-7

Wolf, D. A. \& Foshee, V. A. (2003). Family violence, anger expression styles, and adolescent dating violence. Journal of Family Violence, 18(6), 309-316. Recuperado de http://link.springer.com/article/1 $0.1023 \% 2 F A \% 3$ A1026237914406

Wolfe, D. A., Crooks, C., Chiodo, D., Hughes, R., \& Ellis, W. (2009). Observations of adolescent peer resistance skills following a classroom-based healthy relationship program: A post-intervention comparison. Prevention Science, 13(2), 196-205. doi: 10.1007/s11121-011-0256-z.

Wolfe, D. A., Crooks, C., Jaffe, P., Chiodo, D., Hughes, R., Ellis, W., Stitt, L., \& Donner, A. (2009). A school-based program to prevent adolescent dating violence. Archives of Pediatric \& Adolescent Medicine, 163(8), 692-699. doi: 10.1001/ archpediatrics.2009.69.

Recebido em: 26/05/2014

Reformulado em: 20/08/2015 Aprovado em: 27/08/2015 
Nota dos autores:

Projeto contemplado com bolsa de Produtividade em Pesquisa pelo CNPq para o triênio 2011-2013 (Processo 306975/2010-6). Os autores agradecem ao CNPq fomento concedido para esta pesquisa (Processo 402579-2010-0), bem como bolsas de iniciação científica para o segundo e terceiro autores.

Nossos agradecimentos a Camila Souza Pereira-Guizzo, Bárbara Carvalho Ferreira, Francine dos Santos Teixeira, Daied Vaz Soares, Ana Karoliny Araújo e Raíssa Montenegro Gomes e Martins pelo auxílio na coleta de dados para validação dos instrumentos Escala de Significados da Masculinidade para Adolescentes e Escala de Dificuldades em Regulação das Emoções. Agradecemos ainda a Geovana Nunes de Jesus e Carlos Eduardo Paes Landim Ramos pelo auxílio com o registro dos dados.

Sobre os autores:

Sheila Giardini Murta é docente no Departamento de Psicologia Clínica, orientadora no Programa de Pós-Graduação em Psicologia Clínica e Cultura da Universidade de Brasília e investiga o desenvolvimento, a avaliação, a difusão e a adaptação cultural de programas de promoção de saúde mental e prevenção a riscos para transtornos mentais para pessoas em diferentes fases do ciclo de vida.

E-mail: giardini@unb.br

Rafael Alberto Moore é psicólogo e mestre em Psicologia Social e do Trabalho pela Universidade de Brasilia. E-mail:faelmoore@hotmail.com

Ana Aparecida Vilela Miranda é psicóloga e mestranda em Psicologia Clínica e Cultura pela Universidade de Brasilia. E-mail:aavmiranda@gmail.com

Eudes Diógenes Alves Cangussú é graduado em Psicologia pela Universidade de Brasília.

E-mail: eudesdac@gmail.com

Karine Brito dos Santos é doutoranda do Programa de Pós-graduação em Psicologia Clínica e Cultura, mestre em Psicologia Social, do Trabalho e das Organizações pela Universidade de Brasilia e atua no desenvolvimento de estratégias de prevenção à violência no namoro entre adolescentes.

E-mail:karine-brito@hotmail.com

Karinne Leissa Torres Bezerra é graduada em Psicologia pela Universidade de Brasilia.

E-mail:karinne.leissa@gmail.com

Lydia Galdino Veras é graduada em Psicologia pela Universidade de Brasília.

E-mail: lydia.galdino@gmail.com

Contato com os autores:

Sheila Giardini Murta

Departamento de Psicologia Clínica, Instituto de Psicologia, Universidade de Brasília, Campus Darcy Ribeiro

CEP: 70910-900

Brasilia-DF, Brasil

Psico-USF, Bragança Paulista, v. 21, n. 2, p. 381-393, mai./ago. 2016 